\title{
Selection of oleuropein-degrading lactic acid bacteria strains isolated from fermenting Moroccan green olives
}

\author{
By N. Ghabbour, ${ }^{a}$ Z. Lamzira, ${ }^{a}$ P. Thonart, ${ }^{b}$ P. Cidalia, ${ }^{c}$ M. Markaoui ${ }^{d}$ and A. Asehraou ${ }^{a^{*}}$ \\ aLaboratory of Biology of Plants and Microorganisms, Department of Biology, Faculty of Sciences, \\ University of Mohamed $1^{\text {st }}$, Oujda 60000 , Morocco. \\ ${ }^{b}$ Centre Wallon de Biologie Industrielle, Faculté universitaire des Sciences Agronomiques, \\ 5030 Gembloux, Belgium. \\ 'INIA/ITQB, New University of Lisbon, Ap 127, 2780 Oeiras, Portugal \\ 'Laboratory of Biochemistry, Department of Biology, Faculty of Sciences, \\ University of Mohamed 1st, Oujda, Morocco. \\ ( ${ }^{*}$ Corresponding author: asehraou@yahoo.fr)
}

\section{RESUMEN}

Selección de cepas de bacterias ácido lácticas que degradan oleuropeína aisladas en la fermentación de aceitunas verdes marroquíes.

Un total de 177 cepas de bacterias ácido lácticas (LAB) fueron aisladas en las primeras etapas de la fermentación de aceitunas verdes marroquíes Picholine, incluyendo Lactobacillus plantarum (44.63\%), Lactobacillus pentosus (25.99\%), Lactobacillus brevis $(9.61 \%)$ y Pediococcus pentosaceus (19.77\%). Todos los aislados fueron evaluados mediante su tolerancia a extractos de hojas de olivo y oleuropeína. La mayoría de los aislados $(85,3 \%)$ degradaron oleuropeína, cuando fueron evaluados usando oleuropeína o 5-Bromo-4-cloro-3-indolil $\beta$-D-glucuronido (X-Gluc) como sustrato. La capacidad de biodegradación de las cepas seleccionadas para cada especie fue confirmada mediante análisis por HPLC.

PALABRAS CLAVE: Aceituna - Bacteria ácido láctica Fermentación - $\beta$-glucosidasa - Oeluropeína.

\section{SUMMARY}

Selection of oleuropein-degrading lactic acid bacteria strains isolated from fermenting Moroccan green olives.

A total of 177 strains of lactic acid bacteria (LAB) were isolated from early-stage Moroccan Picholine green olive fermentation, including Lactobacillus plantarum (44.63\%), Lactobacillus pentosus (25.99\%), Lactobacillus brevis (9.61\%) and Pediococcus pentosaceus (19.77\%). All the isolates were screened for their tolerance to olive leaf extract and oleuropein. Most of the isolates (85.3\%) were found able to degrade oleuropein, when evaluated by either oleuropein or 5-Bromo4-chloro-3-indolyl $\beta$-D-glucuronide (X-Gluc) as substrates. The biodegradation capacity of the selected strains of each species was confirmed by HPLC analysis.

KEY-WORDS: Fermentation - $\beta$-glucosidase - Lactic acid bacteria - Oleuropein - Olive.

\section{INTRODUCTION}

Oleuropein, a heterosidic ester of B-glucosylated elenolic acid and 3,4-dihydroxy-phenylethanol (hydroxytyrosol), is the main natural phenolic compound responsible for the bitterness of unripe olives (Kailis and Harris, 2007). Its content in olives is affected by the cultivar, culture conditions and degree of ripeness (Amiot el al., 1986). Debittering green olives is necessary in order to facilitate their transformation into an edible product. The main conventional method of green table olive preparation is based on the alkali-treatment of fruits to assure their complete debittering (Fernandez Diez et al., 1985). However, this chemical treatment, assuring the chemical degradation of oleuropein, leads to high losses in the nutrient values of the processed olives (Kailis and Harris, 2007).

Oleuropein is well known for its antimicrobial activity, particularly against lactic acid bacteria (LAB) (Fleming et al., 1973; Ruiz Barba et al., 1993; Medina et al., 2008), highly desired to assure the lactic fermentation of green olives (Asehraou et al., 1993; Fernandez Diez et al., 1985). L. plantarum is the most frequently studied species for its resistance and the biodegradation capacities of oleuropein and other phenolic compounds in olives (Ciafardini et al., 1994; Marsilio et al., 1996; Rozes and Peres, 1996; Marsilio and Lanza, 1998; Rodriguez et al., 2009). However, limited studies have been done on the influence of these compounds on other LAB species associated with the natural olive I fermentation process, including L. pentosus; L. brevis and P. pentosaceus (Rodriguez et al., 2009). Extending the study of oleuropein biodegradation to other lactic acid bacteria species associated with the natural fermentation process may lead to the selection of lactic starters more potentially active in biological debittering and to improving the sensorial characteristics of fermented olives.

Several studies have demonstrated the beneficial effects of oleuropein for its hypotensive, hypoglycaemic, antibacterial and antiviral activities (Gonzalez et al., 1992; Hansen et al., 1996; Manna et al., 2002) and for its antioxidant activity and its capacity to lower blood pressure (Zarzuelo et al., 1991). Therefore, the preparation of table olives, 
containing the acceptable bitterness of oleuropein and its degradation products, will improve the nutritional value of processed olives and their beneficial effects on consumer health. The main objective of this work is the selection of LAB strains degrading oleuropein from a pool of bacterial strains isolated from the natural fermentation of non-debittered green olives.

\section{MATERIALS AND METHODS}

\subsection{Isolation of lactic acid bacteria strains}

The LAB strains used in this work were isolated from the early stage of the natural fermentation of the non-debittered Moroccan Picholine green olive variety conducted at industrial scale. A volume of $0.1 \mathrm{ml}$ of brine was streaked on the Man, Rogosa and Sharpe (MRS) agar medium (BIOKAR Diagnostics) supplemented with cycloheximide $(0.01 \%, w / v)$ (Sigma Aldrich). The cultures were then incubated at $30^{\circ} \mathrm{C}$ for three days. The isolates showing a Gram positive stain, no spore-forming cells and a catalase negative reaction were selected and then purified on MRS agar and stored at $4^{\circ} \mathrm{C}$ for further studies.

\subsection{Identification of $L A B$ strains}

The LAB strains isolated (177 strains) were identified according to their morphological, physiological and biochemical characteristics (Sharpe et al., 1979; Kandler and Weiss, 1986). The tests used were Gram stain, cell form, catalase reaction, gas production and carbohydrate metabolism. The carbohydrate metabolism was studied using the API50 CH gallery procedure as described by the manufacturer (BIOMERIEUX, France). The names of the species were graciously provided by the BIOMERIEUX (France) company using their own API identification software database.

\subsection{Olive leaf extract and Oleuropein tolerance}

A volume of $5 \mu \mathrm{l}$ of an overnight culture, at $10^{5}$ $\mathrm{cfu} / \mathrm{ml}$ of each LAB strain was spotted on MRS agar supplemented with olive leaf extract $(3,4,5,6,8$ and $10 \%, w / v)$ and oleuropein (1\%, w/v) (Extrasynthese, Genay, France). The Olive Leaf Extract (OLE) was obtained by dehydrating olive leaves at $105^{\circ} \mathrm{C}$ for 24 hours and then grinded with an ultraturax type IKA (WERNE, Germany). The incubation of the assays, made in duplicate on 177 strains, was done at $30^{\circ} \mathrm{C}$ for 3 days. Only strains developing colonies on the medium were considered tolerant to OLE or oleuropein. All the assays were compared to a control not supplemented with OLE or oleuropein.

\subsection{Detection of oleuropein biodegradation}

\section{Use of X-Gluc as substrate}

A volume of $0.2 \mathrm{ml}$ of $0.3 \%(\mathrm{w} / \mathrm{v}$, dissolved in $\mathrm{N}, \mathrm{N}$-dimethylformamide) of 5-bromo-3-indolyl- $\beta$ -
D-glucoside (X-Gluc) (Sigma Aldrich) was spread onto an MRS agar medium, and then inoculated by spreading $5 \mu$ l of an overnight culture of each LAB strain tolerating $10 \%(\mathrm{w} / \mathrm{v})$ of OLE and $1 \%$ $(w / v)$ of oleuropein. The incubation of the plates, made in duplicate on 156 strains, was done at $30^{\circ} \mathrm{C}$ for 7 days. The colonies of the strains producing $\beta$-glucosidase display a blue color.

\section{Use of oleuropein as substrate}

The LAB strains tolerating oleuropein (156 strains) were inoculated by spreading $5 \mu$ l of an overnight culture on modified MRS agar containing (g/l): oleuropein, 10; pepton, 10; yeast extract, 4; dipotassium phosphate, 2; diamonium citrate, 2; sodium acetate 1.5; magnesium sulfate, 0.2; manganese sulphate, 0.05;Tween $80,1 \mathrm{ml}$ and agar, 15. The final $\mathrm{pH}$ of the medium was adjusted to 7.4. The incubation of the assays, made in duplicate, was done at $30^{\circ} \mathrm{C}$ for 7 days. The strains developing colonies on the medium were considered able to use oleuropein as the sole carbon source.

\subsection{Oleuropein biodegradation confirmation}

Four LAB strains showing high oleuropein biodegradation and $X-G l u c$ reaction capacities were inoculated in modified MRS broth containing oleuropein $(1 \%, w / v)$ as the sole carbon source. The final $\mathrm{pH}$ of the medium was adjusted to 7.4. 5 $\mu$ of overnight cultures of about $10^{5} \mathrm{cfu} / \mathrm{ml}$ of each LAB strain; they were inoculated separately in $5 \mathrm{ml}$ of modified MRS broth and then incubated at $30^{\circ} \mathrm{C}$ for 7 days. The control consisted of $5 \mathrm{ml}$ of noninoculated, modified MRS broth incubated in the same conditions as described above. The cultures and the control were then centrifuged at 1000 $\mathrm{rpm} / 10 \mathrm{~min}$, and phenolic compounds were extracted from the supernatant three times with ethyl acetate $(8: 2, v / v)$. After decanting, the organic phase was harvested and left in the dark for 30 minutes in the presence of disodium sulfate and then evaporated to dryness at $50^{\circ} \mathrm{C}$. The residue obtained was dissolved in $1 \mathrm{ml}$ of methanol and then analyzed by an HP isocratic HPLC, with an HP UV detector at $280 \mathrm{~nm}$ and a C18 Supelcogel column $(\mathrm{C}-610 \mathrm{H}$, $30 \mathrm{~cm} \times 7,8 \mathrm{~mm})$ maintained at $40^{\circ} \mathrm{C}$. The mobile phase consisted of acetonitryl-methanol $(1: 1, \mathrm{v} / \mathrm{v})$ (solution A) and milli-Q water acidified with acetic acid to pH 3.2 (solution B). Samples filtered through PVDF syringe filter (Sartorius, France). After filtering, a volume of $20 \mathrm{ul}$ was injected at a flow rate of $1 \mathrm{ml} /$ min. The gradient used was the same as described by Mateos et al., (2001).

\section{RESULTS AND DISCUSSION}

\subsection{Identification of LAB strains}

The LAB strains isolated from the early stage of naturally fermenting non debittered green olives, and identified with 98 to $99.9 \%$ positive results, were 
found to be composed of L. plantarum (44.63\%), $L$. pentosus (25.99\%), P. pentosaceus (19.77\%) and $L$. brevis $(9.61 \%)$. These species are naturally occurring in the natural fermentation of green olives (Fernandez Diez et al., 1985; Hurtado et al., 2008; Rodriguez et al., 2009). The species L. plantarum, L. pentosus and $P$. pentosaceus are highly desired in olive fermentation for their acidification capacity and their homofermentative metabolism lacking gas production (Kandler and Weiss, 1986). The dominance of these homofermentative species indicated the successful development of the natural lactic fermentation process in non debittered Moroccan Picholine green olives. However, L. brevis, characterized by its heterofermentative metabolism, may cause bloater spoilage in olives (Kailis and Harris, 2007).

\subsection{OLE and oleuropein tolerance}

The results of the OLE and oleuropein tolerance of LAB strains are reported on table 1. All the species studied showed high levels of tolerance, ranging from $73.53 \%$ and $95.57 \%$ for OLE (up to $10 \%$ ), and $73.52 \%$ and $94.30 \%$ for oleuropein (1\%). OLE is more tolerated than oleuropein, which may be due to lower concentrations of oleuropein in OLE.

Most phenolic compounds in olives, particularly oleuropein, are known for their antimicrobial effect on LAB growth (Ciafardini et al., 1994; Landete et al., 2008; Rodriguez et al., 2009). However, the high levels of tolerance obtained with these LAB strains may be explained by their natural selection during the spontaneous lactic fermentation of non debittered green olives.

The strains of L. plantarum, L. pentosus and $P$. pentosaceus, characterized by their homofermentative metabolism, showed high tolerance to OLE and oleuropein. The strains of $L$. brevis showed the lowest tolerance level. From a technological point of view, the dominance of $L$. plantarum, $L$. pentosus and $P$. pentosaceus, and their tolerance to OLE (up to $10 \%$, $\mathrm{w} / \mathrm{v})$ and oleuropein $(1 \%, \mathrm{w} / \mathrm{v})$, suggest their possible use as starters in the controlled fermentation of non debittered green olives.

\subsection{Detection of oleuropein biodegradation}

Among the species showing high levels of OLE and oleuropein tolerance, about $14.74 \%$ were not able to degrade either oleuropein or X-Gluc (Table 2). The other LAB strains (85.26\%) showed a $\beta$-glucosidase activity, with a slight difference between the two methods, which may be due to the visual evaluation of growth and the blue color developed. L. plantarum showed the highest percent of strains producing $\beta$-glucosidase and degrading oleuropein as the sole carbon source, followed by $L$. pentosus, $P$. pentosaceus and $L$. brevis. The biodegradation of oleuropein is based on the production of $\beta$-glucosidase, leading to the

Table 1

Olive leaf extract and oleuropein (1\%) tolerance of LAB strains isolated from naturally fermenting green olives

\begin{tabular}{lccccc}
\hline \multirow{2}{*}{ Species } & \multicolumn{3}{c}{ olive leaf extract $(\%, w / v)$} & \multicolumn{1}{c}{ oleuropein $(\%$, w/v) } \\
\cline { 2 - 6 } & $\mathbf{0}$ & $\mathbf{6}$ & $\mathbf{8}$ & $\mathbf{1 0}$ & $\mathbf{1}$ \\
\hline L. plantarum & $100^{\star}( \pm 0.0)^{\star *}$ & $100( \pm 0.0)$ & $97.47( \pm 1.26)$ & $95.57( \pm 1.89)$ & $94.30( \pm 0.63)$ \\
L. pentosus & $100( \pm 0.0)$ & $100( \pm 0.0)$ & $95.65( \pm 2.17)$ & $90.22( \pm 1.06)$ & $88.04( \pm 1.08)$ \\
L. brevis & $100( \pm 0.0)$ & $100( \pm 0.0)$ & $97.06( \pm 2.94)$ & $73.53( \pm 2.94)$ & $73.52( \pm 2.94)$ \\
$P$. pentosaceus & $100( \pm 0.0)$ & $100( \pm 0.0)$ & $97.14( \pm 2.85)$ & $87.14( \pm 1.42)$ & $84.28( \pm 1.42)$ \\
\hline
\end{tabular}

*: percent of strains tolerating olive leaf extract and oleuropein, ${ }^{* *}:$ Standard deviation

Table 2

Detection of $\beta$-glucosidase production, using Oleuropein and X-Gluc as substrates, by lactic acid bacteria strains isolated from fermenting green olives

\begin{tabular}{lccccccccc}
\hline \multicolumn{1}{c}{ Species } & No & \multicolumn{4}{c}{ Oleuropein } & \multicolumn{4}{c}{ X-Gluc } \\
\hline & & ++++ & ++ & + & - & +++ & ++ & + & - \\
\hline L. plantarum & 74 & $31.75^{\star}( \pm 0.67)^{\star *}$ & $39.18( \pm 1.35)$ & $15.54( \pm 2.03)$ & $13.51( \pm 0.0)$ & $31.41( \pm 0.67)$ & $37.83( \pm 1.35)$ & $18.24( \pm 2.02)$ & $13.51( \pm 0.0)$ \\
L. pentosus & 41 & $25.61( \pm 1.21)$ & $40.24( \pm 1.21)$ & $21.95( \pm 0.0)$ & $12.2( \pm 0.0)$ & $26.83( \pm 0.0)$ & $40.24( \pm 3.65)$ & $20.73( \pm 3.65)$ & $12.19( \pm 0.0)$ \\
L. brevis & 12 & $20.83( \pm 4.16)$ & $29.16( \pm 4.16)$ & $25( \pm 0.0)$ & $25( \pm 0.0)$ & $16.67( \pm 0.0)$ & $37.5( \pm 4.16)$ & $20.83( \pm 4.16)$ & $25( \pm 0.0)$ \\
P. pentosaceus & 29 & $22.41( \pm 1.72)$ & $44.82( \pm 3.44)$ & $15.51( \pm 1.72)$ & $17.24( \pm 0.0)$ & $18.97( \pm 1.72)$ & $46.55( \pm 1.72)$ & $17.24( \pm 0.0)$ & $17.24( \pm 0.0)$ \\
\hline
\end{tabular}

No: number of strains, *: percent of strains showing positive (growth or blue color production) or negative reaction; for oleuropein biodegradation: +++ : high growth, ++: medium growth, +: weak growth and -: no growth; for X-Gluc biodegradation (reaction): +++: high biodegradation (intense blue color), ++ : medium biodegradation (medium blue color), + : weak biodegradation (weak blue color), -: non biodegradation (no blue color), ${ }^{* *}$ : standard deviation. 
release of glucose and other phenolic compounds (Ciafardini et al., 1994). This finding indicates the possible use of one of these methods for the rapid detection of LAB strains degrading oleuropein.

\subsection{Oleuropein biodegradation confirmation}

The chromatographic patterns obtained from the extracts of modified MRS broth, containing oleuropein as the sole carbon source, after 7 days of incubation of the four LAB strains studied are reported in Figures $3,4,5$ and 6 . The oleuropein and its degradation products were identified by comparison of their retention times to standards (Figures 1 and 2). The results obtained with the four LAB strains showed a drastic reduction in oleuropein accompanied by the accumulation of other phenolic compounds, mainly hydroxytyrosol (Figures 3, 4,5 and 6). The accumulation of hydroxytyrosol was reported as the main degradation product of oleuropein and stable at a low pH (Ciafardini et al., 1994; Landete et al., 2007, Rodriguez et al., 2009). This finding clearly demonstrates the oleuropein biodegradation capacity of the studied LAB strains.

The peaks of hydroxytyrosol obtained with $L$. plantarum (S137) (Figure 3) and L. pentosus (S84) (Figure 4) are more important than those obtained with L. brevis (S15) (Figure 5) and P. pentosaceus (S3) (Figure 6). These results may be due to the high degradation capacity of L. plantarum (S137) and L. pentosus (S84) compared to L. brevis (S15) and $P$. pentosaceus (S3). The absence of glucose in the medium, previously reported for its partial inhibitory effect on the $\beta$-glucosidase activity of LAB

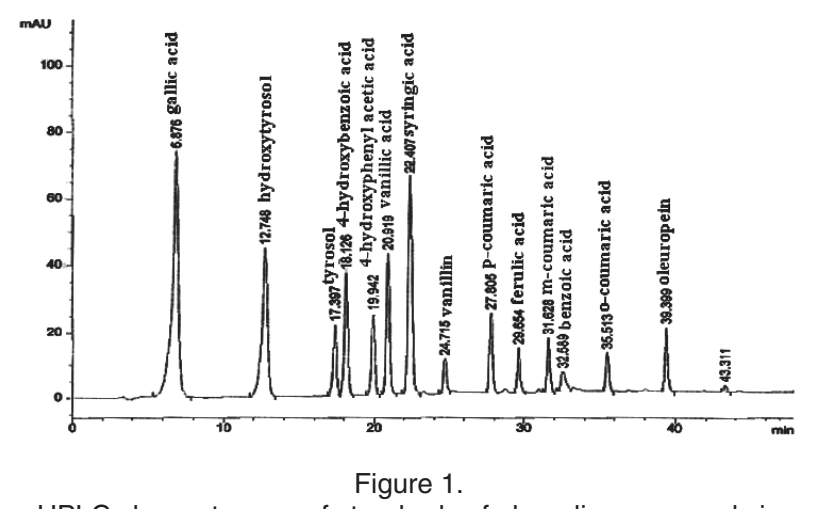

HPLC chromatogram of standards of phenolic compounds in methanol.

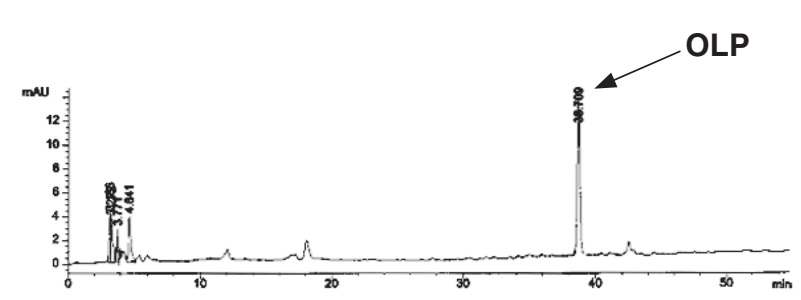

Figure 2

Chromatogram of phenolic compounds in non inoculated modified MRS medium (control) after 7 days of incubation at $25^{\circ} \mathrm{C}$. Legend: OLP $=$ oleuropein. strains (Ciafardini et al., 1994), may explain the high biodegradation capacity obtained.

Other phenolic compounds, identified by the comparison of their retention times to the standards (Figure 1), mainly tyrosol, gallic acid, p-coumaric acid and ferulic acid, were detected with variable importance in the cultures of $L$. brevis and $P$. pentosaceus (Figures 5 and 6). However, most of these compounds were not detected in the cultures of L. plantarum and L. pentosus (Figures 3 and 4), which may be due to their biodegradation by these LAB strains as reported in the literature (Rodriguez et al., 2008a, 2008b).

The biodegradation of oleuropein to hydroxytyrosol and other simple phenolic compounds by $L$. plantarum, involving $\beta$-glucosidase and esterase enzymes, was previously reported (Ciafardini et al., 1994; Marsilio et al., 1996; Marsilio and Lanza, 1998; Landete et al., 2008; Rodriguez et al., 2009). The accumulation of these simple phenolic compounds, mainly hydroxytyrosol, is highly desired because they increase the safety, nutritional and shelf-life properties of fermented olives (Visioli et al., 1995; Ordoudi and Tsimidou, 2006; Rodriguez et al., 2009).

\section{CONCLUSIONS}

The selection of $\mathrm{LAB}$ strains tolerating and degrading oleuropein from their natural environment, the natural lactic fermentation of non-debittered green olives, led to the selection of a high percentage of strains tolerating and degrading oleuropein. The use of oleuropein and X-Gluc as substrates gave rapid and slightly similar results in detecting the

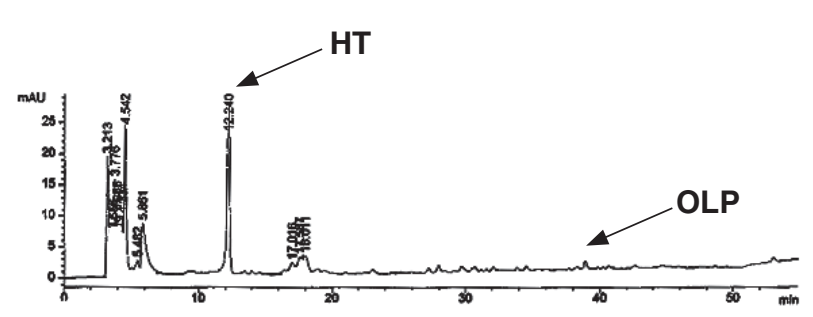

Figure 3

HPLC chromatogram of phenolic compounds produced in modified MRS medium (containing $1 \%$ of OLP as the sole carbon source) by L. plantarum (S137) after 7 days of culture at $25^{\circ} \mathrm{C}$. Legends: OLP = oleuropein, $\mathrm{HT}=$ hydroxytyrosol.

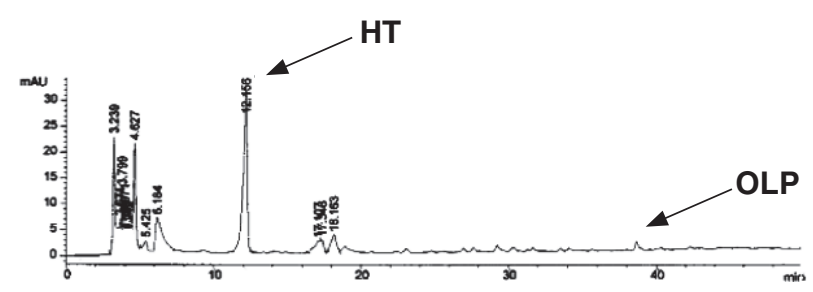

Figure 4

HPLC chromatogram of phenolic compounds produced in modified MRS medium (containing $1 \%$ of OLP as the sole carbon source) by L. penstosus (S84) after 7 days of culture at $25^{\circ} \mathrm{C}$. Legends: OLP = oleuropein, $\mathrm{HT}=$ hydroxytyrosol. 


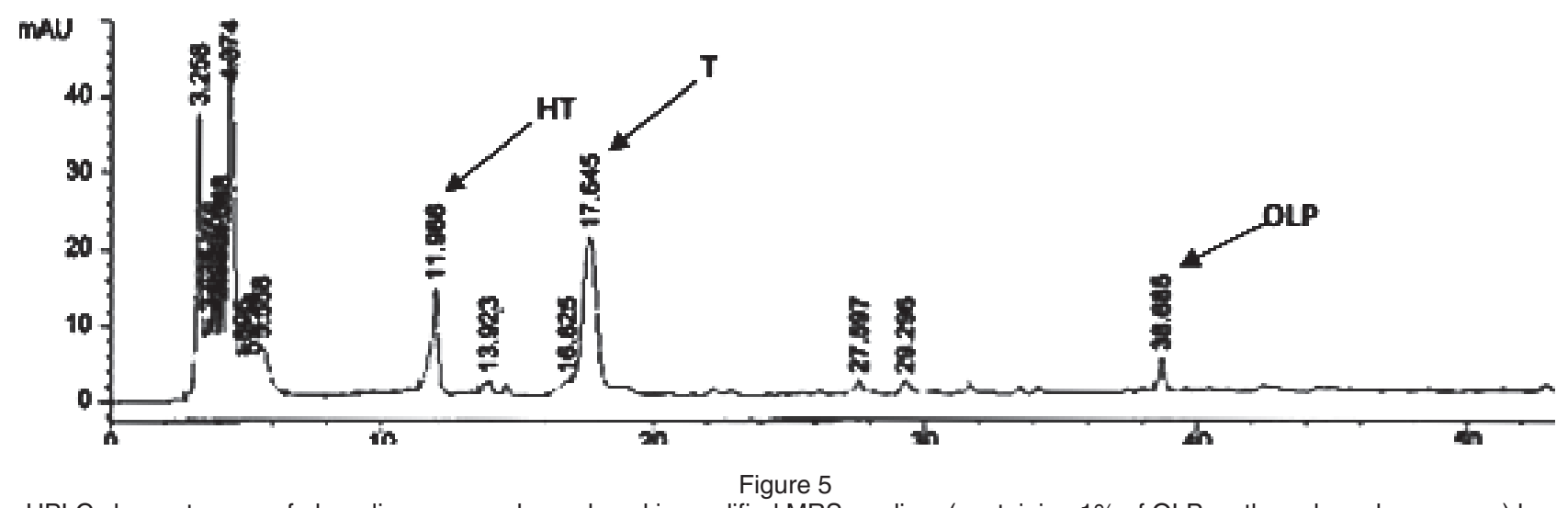

HPLC chromatogram of phenolic compounds produced in modified MRS medium (containing $1 \%$ of OLP as the sole carbon source) by L. brevis (S15) after 7 days of culture at $25^{\circ} \mathrm{C}$. Legends: OLP = oleuropein, $\mathrm{HT}=$ hydroxytyrosol, $\mathrm{T}=$ tyrosol.

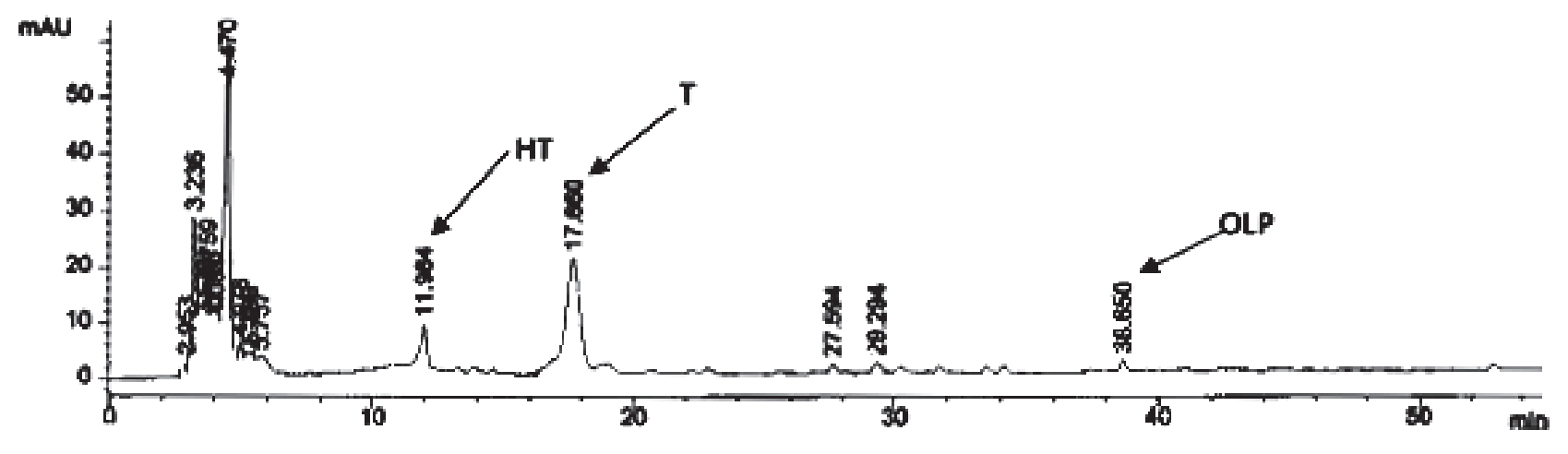

Figure 6

HPLC chromatogram of phenolic compounds produced in modified MRS medium (containing $1 \%$ of OLP as the sole carbon source) by P. pentosaceus (S3) after 7 days of culture at $25^{\circ} \mathrm{C}$. Legends: OLP = oleuropein, $\mathrm{HT}=$ hydroxytyrosol, $\mathrm{T}=$ tyrosol.

biodegradation capacity of $L A B$ strains, including $L$. plantarum and $L$. pentosus and other LAB species ( $L$. brevis and $P$. pentosaceus) associated with the natural fermentation process of green olives. The oleuropein biodegradation capacity of the selected LAB species, demonstrated by HPLC analysis, indicated their possible use as starters or their $\beta$-glucosidase enzyme to perform the biological elaboration of green table olives with improved sensorial and nutritional characteristics.

\section{ACKNOWLEDGEMENTS}

The authors are grateful to the 'Commission Universitaire pour le Développement' (Belgium), the ICCTI(Portugal) and CNRST (Morocco) for financial support of this work. The authors would like to thank BIOMERIEUX (France) for their help with the identification of lactic acid bacteria species.

\section{REFERENCES}

Amiot M, Fleuriet A, Macheix J. 1986. Importance and evolution of phenolic compounds in olive during growth and maturation. J. Agric. Food Chem. 34, 823-826.

Asehraou A, Faid M, Akhartouf R. 1993. Pure culture fermentation of green olives by lactobacilli strains. Microbiologie-Aliments-Nutrition 11, 221-228.
Ciafardini G, Marsilio V, Lanza B, Pozzi N. 1994. Hydrolysis of oleuropein by Lactobacillus plantarum strains associated with olive fermentation. Appl. Environ. Microbiol. 60, 4142-4147.

Fernandez-Diez MJ, Castro Ramos R, Garrido Fernandez A, Heredia Moreno A, Minguez Mosquera MI, Rejano Navarro L, Duran Quintana MC, Gonzalez Cancho F, Gomez Millan A, Garcia Garcia P, Sanchez Oldan F. 1985. Biotechnology of Table Olives. Instituto de la Grasa y sus Derivados, Sevilla, Spain.

Fleming HP, Walter WM, Etchells JL. 1973. Antimicrobial proprieties of oleuropein and products of its hydrolysis from green olives. J. Appl. Microbiol. 26, 777-782.

Gonzalez M, Zarzuelo A, Gamez MJ, Utrilla MP, Jimenez J, Osuna I. 1992. Hypoglycemic activity of olive leaf. Planta Med. 58, 513-515.

Hansen K, Adsersen A, Christensen BS, Brooegger S, Rosendal JS, Nyman U, Wagner SU. 1996. Isolation of an angiotensin converting enzyme (ACE) inhibitor from Olea europaea and Olea lancea. Phytomedicine 2, 319-324.

Hurtado A, Reguant C, Esteve-Zarzoso B, Bordons A, Rozes N. 2008. Microbial population dynamics during the processing of Arbequina table olives. Food Res. Int. 41, 738-744.

Kailis S, Harris D. 2007. Table olive processing: general aspects. In: Producing table olives. CSIRO publishing, Landlinks Press, Collingwood, Australia, pp. 131-189.

Kandler O, Weiss N. 1986. Regular, Nonsporing, Grampositive rods. In: Bergey's Manual of Systematic Bacteriology. Ed: Sneath PHA, Mair NC, Sharpe ME, 
Holt JG. Vol. 2, William and Wilkins, Baltimore, pp. 1208-1234.

Landete JM, Curiel JA, Rodriguez H, de las Rivas B, Munoz R. 2008. Study of the inhibitory activity of phenolic compounds found in olive products and their degradation by Lactobacillus plantarum strains. Food Chem. 107, 320-326.

Landete JM, Rodriguez $\mathrm{H}$, de las Rivas B, Munoz R. 2007. High-added-value antioxidants obtained from the degradation of wine phenolics by Lactobacillus plantarum. J. Food Protect. 70, 2670-2675.

Manna C, D’Angelo S, Migliardi V, Loffredi E, Mazzoni O, Morrica P, Galletti P, Zappia V. 2002. Protective effect of the phenolic fraction from virgin olive oils against oxidative stress in human cells. J. Agric. Food Chem. 50, 6521-6526.

Marsilio V, Lanza B, Pozzi N. 1996. Progress in table olive debittering: degradation in vitro of oleuropein and its derivatives by Lactobacillus plantarum. Journal of AOCS 73, 593-597.

Marsilio V. Lanza B. 1998. Characterization of an oleuropein degrading strain of Lactobacillus plantarum. Combined effects of compounds present in olive fermenting brines (phenols, glucose and $\mathrm{NaCl}$ ) on bacterial activity. J. of Sci. of Food and Agric. 76, 520-524.

Mateos R, Espartero JL, Trujillo M, Rios JJ, LeonCamacho M, Alcudia F, Cert A. 2001. Determination of phenols, flavones, and lignans in virgin olive oils by solid-phase extraction and high-performance liquid chromatography with diode array ultraviolet detection. J. Agric. Food Chem. 49, 2185-2192.

Medina E, Romero C, Castro A, Brenes M, Garcia A. 2008. Inhibitors of lactic acid fermentation in Spanishstyle green olive brines of the Manzanilla variety. Food Chem. 110, 932-937.
Ordoudi SA, Tsimidou MZ. 2006. Crocin bleaching assay (CBA) in structure-radical scavenging activity studies of selected phenolic compounds. J. Agric. Food Chem. 54, 9347-9356.

Rodriguez H, Curiel JA, Landete JM, de las Rivas B, de Felipe FP, Cordoves CG, Mancheno JM, Munoz R. 2009. Food phenolics and lactic acid bacteria. Int. J. Food Microbiol. 132, 79-90.

Rodriguez H, Landete JM, Curiel JA, de las Rivas B, Mancheno JM, Munoz R. 2008a. Characterization of the p-coumaric acid decarboxylase from Lactobacillus plantarum CECT 748T. J. Agric. Food Chem. 56, 3068-3072.

Rodriguez H, Landete JM, de las Rivas B, Munoz R. 2008b. Metabolism of food phenolic acids by Lactobacillus plantarum CECT 748T. Food Chem. 107, 1393-1398.

Rozes N, Peres C. 1996. Effect of oleuropein and sodium chloride on viability and metabolism of Lactobacillus plantarum. Appl. Microbiol. Biotechnol. 45, 839-843.

Ruiz-Barba JL, Brenes-Balbuena M, Jimenez-Diaz R, Garcia-Garcia P, Garrido-Fernandez A. 1993. Inhibition of Lactobacillus plantarum by polyphenols extracted from two different kinds of olive brine. J. Appl. Microbiol. 74, 15-19.

Sharpe ME, Fryer TF, Smith DG. 1979. Identification of lactic acid bacteria. In: Identification Methods for Microbiologists, Gibbs EM and Skiner F A (Eds), Academic Press, London, pp. 233-259.

Visioli F, Bellomo G, Montedoro G, Galli C. 1995. Low density lipoprotein oxidation is inhibited in vitro by olive oil constituent. Atherosclerosis 117, 25-32.

Zarzuelo A, Duarte J, Jimenez J, Gonzales M, Utrilla M. P. 1991. Vasodilator effect of olive leaf. Planta Med. $57,417-419$

Recibido: $5 / 5 / 10$ Aceptado: $28 / 6 / 10$ 